\title{
MODELTEAM GAME TOURNAMENT (TGT) BERBANTUAN MEDIA KARTU SOAL BERBASIS HOTS TERHADAP HASIL BELAJAR MAHASISWA
}

\author{
Florentina M. Panda1); Catur F. Djarwo ${ }^{2)}$ \\ 1).Universitas Cenderawasih, Jl. Raya Abepura-Sentani; florentinapanda88@gmail.com \\ 2).Universitas Cenderawasih, Jl. Raya Abepura-Sentani; caturdjarwo@ gmail.com
}

\begin{abstract}
The atomic structure material has certain characteristics and difficulties, including the need for a lot of knowledge and analytical skills that students have. Therefore, students need to be given the right learning model in order to increase their interest and learning activities. The learning model that can be done is to carry out learning by applying a cooperative approach, one of which is the Team Game Tournament (TGT) type. The effectiveness of using the TGT model can be increased by providing question cards media. The question card media used in this study is a card containing Higher Order Thinking Skill (HOTS) questions that require students' higher order thinking skills.

The purpose of this study was to determine the effectiveness of using the TGT type cooperative learning model with the help of HOTS-based question card media on atomic structure material on higher-order thinking skills and student learning outcomes of physics education.Based on the results of research and calculations, it can be concluded that the provision of question card media in the TGT model on the atomic structure material is effective on student learning outcomes with Sig values. (0.028) $<0.05$, then there is a difference in learning outcomes so that it can be concluded that the experimental class is more effective than the control class. Supported by the highest lowest scores in the experimental group, namely 75 and 100 with an average of 90.02, while the control group was 65 and 100 with an average of 84.2 .
\end{abstract}

Keywords: TGT, Question Cards; HOTS, Learning Outcome;, and Atomic Structure

\begin{abstract}
ABSTRAK
Materi Struktur atom memiliki karakteristik dan kesulitan tertentu, diantaranya adalah perlu banyak pengetahuan dan kemampuan analisis yang dimiliki peserta didik Oleh karena itu peserta didik perlu diberikan model pembelajaran yang tepat agar dapat meningkatkan minat dan aktivitas belajarnya. Model pembelajaran yang dapat dilakukan yakni melaksanakan pembelajaran dengan menerapkan pendekatan kooperatif, salah satunya yakni tipe Team Game Tournament (TGT). Efektifitas pengunaan model TGT dapat ditingkatkan dengan pemberian media kartu soal. Media kartu soal yang digunakan dalam penelitian ini adalah kartu yang berisi soal-soal Higher Order Thinking Skill (HOTS) yang menuntut keterampilan berpikir tingkat tinggi peserta didik.

Tujuan dari penelitian ini adalah untuk mengetahui efektifitas penggunaan model pembelajaran kooperatif tipe TGT berbantuan media kartu soal berbasis HOTS pada materi struktur atom terhadap kemampuan berpikir tingkat tinggi dan hasil belajar peserta didik pendidikan fisika. Berdasarkan hasil penelitian dan perhitungan maka dapat diambil kesimpulan pemberian media kartu soal dalam model TGT pada materi Struktur atom efektif terhadap hasil belajar peserta didik dengan nilai nilai Sig. $(0,028)<0,05$, maka ada perbedaan hasil belajar sehingga dapat disimpulkan kelas eksperimen lebih efektif daripada kelas kontrol. Didukung dengan nilai terendah tertinggi kelompok eksperimen, yaitu 75 dan 100 dengan rata-rata 90,02, sedangkan kontrol 65 dan 100 dengan rata-rata 84,2.
\end{abstract}

Kata Kunci: TGT, Kartu Soal, HOTS, Hasil Belajar, dan Struktur Atom. 


\section{PENDAHULUAN}

Pedoman penyelenggaraan kegiatan pembelajaran perlu disusun secara relevan berdasarkan tujuan, program pendidikan, sistem penyampaian, dan evaluasi oleh dosen yang mengajar. Peranan dosen dalam keberhasilan pembelajaran harus mampu meningkatkan hasil belajar mahapeserta didik, khususnya mata kuliah kimia dasar yang kurang diminati. Kimia dasar merupakan salah satu mata kuliah yang dipelajari mahapeserta didik pendidikan kimia, namun mata kuliah ini juga diperoleh oleh peserta didik pendidikan fisika di Fakultas Keguruan dan Ilmu Pendidikan Universitas Cenderawasih.

Pokok bahasan yang terdapat dalam materi kuliah kimia umum salah satunya adalah struktur atom. Struktur atom adalah perhitungan kimia yang menggambarkan semua aspek kuantitatif dari komposisi dan reaksi kimia. Pemahaman konsep-konsep dalam pokok bahasan struktur atom perlu dipahami dengan baik karena menjadi dasar untuk penguasaan konsep pada materi selanjutnya, sehingga diperlukan pengetahuan dan kemampuan analisis yang dimiliki mahapeserta didik. Oleh karena itu mahapeserta didik perlu diberikan model pembelajaran yang tepat agar dapat meningkatkan minat dan aktivitas belajarnya. Aktivitas belajar pada dasarnya mengembangkan potensi-potensi yang dimiliki oleh mahapeserta didik. Menurut Rahmawati \& Yonata (2012) Konsep belajar kimia sangat menarik jika bersifat kongkrit dan melibatkan peserta didik secara efektif. Akibatnya, banyak peserta didik Sekolah Menengah Atas (SMA) yang gagal dan kurang tertarik dalam ilmu kimia (Marwah dkk, 2015).

Berdasarkan permasalahan yang ada maka perlu dilakukan upaya untuk hasil belajar mahapeserta didik. Upaya perbaikan yang dapat dilakukan yakni melaksanakan pembelajaran dengan menerapkan pendekatan kooperatif, salah satunya yakni tipe Team Game Tournament (TGT). Menurut Ratumanan, 2004: 138 bahwa model TGT merupakan suatu pembelajaran dimana setelah kehadiran guru, peserta didik pindah kekelompoknya masingmasing untuk menyelesaikan pertanyaanpertanyaan dan mendiskusikan dalam kelompok asal.

Manfaat penggunaan model TGT yaitu peserta didik menjadi lebih aktif, mendidik peserta didik untuk berlatih bersosialisasi dengan orang lain, motivasi belajar peserta didik lebih tinggi, hasil belajar peserta didik lebih baik, dan mengedepankan penerimaan terhadap perbedaan individu (Tyasningsih, dkk. 2012: 2). Efektifitas pengunaan model TGT dapat ditingkatkan dengan pemberian media kartu soal. Media pembelajaran, 
menggunakan bukan untuk berjudi, melainkan suatu media untuk pembelajaran dengan cara permainan kartu, menurut Wijayati, dkk (2009) permainan yang dimaksudkan disini adalah strategi pembelajaran yang seluruh aktivitasnya tetap relevan dengan materi pelajaran sehingga dapat memotivasi, mengurangi kejenuhan serta bersifat menghibur.Media kartu soal yang digunakan dalam penelitian ini adalah kartu yang berisi soal-soal Higher Order Thinking Skill (HOTS) yang menuntut keterampilan berpikir tingkat tinggi mahapeserta didik. Penerapan media kartu soal, mahapeserta didik dilatih untuk mengerjakan latihan-latihan soal berbasis HOTS sambil berdiskusi dengan kelompoknya sehingga dapat meningkatkan keterampilan HOTS dan pemahaman peserta didik tentang materi struktur atom.

Berdasarkan uraian di atas maka telah dilakukan penelitian dengan judul "Efektivitas Model Team Game Tournament Berbantuan Media Kartu Soal Berbasis HOTS terhadap Hasil Belajar Mahapeserta didik pada Materi Struktur Atom".

\section{METODE PENELITIAN}

Data yang telah terkumpul dianalisis secara statistik yaitu uji homogenitas, uji normalitas, dan uji hipotesis. Langkahlangkah yang dilakukan:

\section{A. Uji Homogenitas}

Uji homogenitas dilakukan untuk melihat apakah kelas eksperimen (X) dan kelas kontrol (Y) mempunyai kemampuan rata-rata yang hampir sama atau secara statistik dinyatakan homogen.

Pengujian homogenitas menggunakan uji F (Kadir, 2016: 162). Statistik uji F dituliskan sebagai berikut:

1) Mencari varians/standar deviasi variabel kelas eksperimen dan kelas kontrol.

$$
\begin{gathered}
S_{X}{ }^{2}=\sqrt{\frac{n \sum X^{2}-\left(\sum X\right)^{2}}{n(n-1)}} \\
S_{Y}{ }^{2}=\sqrt{\frac{n \sum Y^{2}-\left(\sum Y\right)^{2}}{n(n-1)}}
\end{gathered}
$$

2) Mencari $F$ hitung dari varians $X$ dan $\mathrm{Y}$, dengan rumus:

$$
\mathrm{F}=\frac{\text { varians terbesar }}{\text { varians terkecil }}
$$

\section{Dengan:}

varians terbesar sebagai pembilang

varians terkecil sebagai penyebut

3) Membandingkan $F_{\text {hitung }}$ dengan $\mathrm{F}_{\text {tabel }}$

- Untuk varians dari kelompok dengan varians terbesar adalah $\mathrm{dk}$ pembilang $\mathrm{n}-1$

- Untuk varians dari kelompok dengan varians terkecil adalah dk penyebut $n-1$

- Kriteria pengujian dengan taraf signifikan $5 \%$. $\mathrm{F}_{\text {hitung }}<\mathrm{F}_{\text {tabel }}$ berarti homogen, $F_{\text {hitung }}>\mathrm{F}_{\text {tabel }}$ berarti tidak homogen.

\section{B. Uji Normalitas}


Uji normalitas ini dilakukan dengan tujuan untuk mengetahui apakah sampel berasal dari populasi yang berdistribusi normal atau tidak. Pengujian normalitas data hasil penelitian menggunakan ChiSquare.

Rumus Uji Chi-Square $\left(\mathrm{X}^{2}\right)$ (Sugiyono, 2017: 107):

$$
X^{2}=\sum_{i=1}^{k} \frac{\left(f_{o}-f_{h}\right)^{2}}{f_{h}}
$$

Keterangan:

$\mathrm{X}^{2}=$ Chi kuadrat

$\mathrm{f}_{\mathrm{o}}=$ frekuensi yang diobservasi

$\mathrm{f}_{\mathrm{h}}=$ frekuensi yang diharapkan

Kriteria pengujian dengan $\alpha=5 \%$ jika $\mathrm{X}^{2}{ }_{\text {hitung }}<\mathrm{X}_{\text {tabel }}^{2}$ maka berdistribusi normal.

\section{Uji Hipotesis}

Uji ini digunakan untuk mengetahui apakah hipotesis diterima atau ditolak. Untuk mengetahui perbedaan hasil belajar mahapeserta didik yang menggunakan media kartu soal dalam model pembelajaran kooperatif tipe TGT dengan peserta didik yang menggunakan model pembelajaran kooperatif tipe TGT tanpa media kartu soal dilakukan uji t. Uji t dilakukan dengan bantuan SPSS, Independent Sample $\mathrm{T}$ Test. Pedoman dalam pengambilan keputusan adalah:

- Jika varians kedua kelas homogen, maka nilai Sig. (2-tailed) equal variances assumed. Kriteria pengujiannya adalah jika Sig. > 0,05 maka $\mathrm{H}_{0}$ diterima yang artinya tidak ada perbedaan antara dua kelompok.
- Jika varians kedua kelas homogen, maka nilai Sig. (2-tailed) equal variances not assumed. Kriteria pengujiannya adalah jika Sig. $<0,05$ maka $\mathrm{H}_{0}$ ditolak yang artinya ada perbedaan antara dua kelompok.

Hasil pengolahan data dan analisis yang dilakukan, dijadikan dasar untuk membuat kesimpulan berdasarkan permasalahan yang diajukan pada rumusan masalah.

\section{HASIL DAN PEMBAHASAN}

Data hasil analisis untuk mengetahui Efektivitas Model Team Game Tournament Berbantuan Media Kartu Soal terhadap Hasil Belajar peserta didik pada Materi Struktur Atom adalah sebagai berikut:

\section{A. Data Hasil Analisis Penelitian}

Untuk mengetahui hasil belajar peserta didik dalam mempelajari materi struktur atom ditunjukkan dengan skor rata-rata kelompok kontrol dan kelompok eksperimen. Ada tidaknya perbedaan skor rata-rata kelompok kontrol dan kelompok eksperimen dapat diketahui melalui uji hipotesis melalui uji $\mathrm{t}$ dengan taraf signifikan 0,05 .

Berikut disajikan deskripsi data hasil belajar dan perbedaan hasil belajar peserta didik antara kelompok eksperimen dengan penerapan 
Jurnal IImu Pendidikan Indonesia 9 (2) : 86- 92 | 90

pembelajaran TGT berbantuan media kartu soal dan kelompok kontrol dengan penerapan pembelajaran TGT tanpa media kartu soal pada tabel 1 dan 2.

Tabel 1. Data Deskripsi Hasil Belajar Mahapeserta didik

Group Statistics

\begin{tabular}{|l|r|r|r|c|}
\hline KELOMPOK & $\mathrm{N}$ & Mean & $\begin{array}{c}\text { Std. } \\
\text { Deviation }\end{array}$ & $\begin{array}{c}\text { Std. } \\
\text { Error } \\
\text { Mean }\end{array}$ \\
\hline KLMPK EKSP. & 35 & 90,200 & 7,9661 & 1,3465 \\
KLMPK KTRL & 34 & 84,147 & 13,7403 & 2,3564 \\
\hline
\end{tabular}

Data dari tabel 1 di analisis perbandingan antara tes akhir hasil belajar peserta didik kelas eksperimen dan kelas kontrol ditunjukkan pada Tabel 2:

Tabel 2. Uji t Perbedaan Hasil Belajar

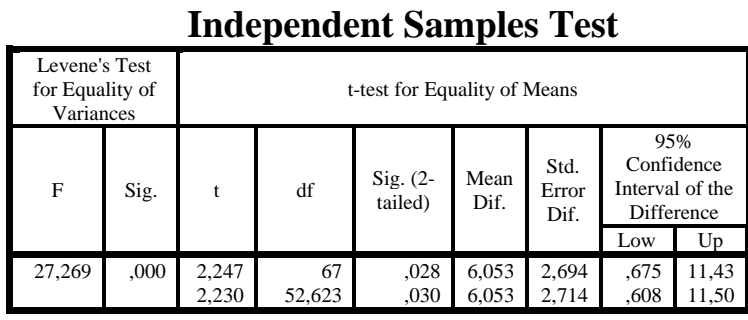

Hasil perhitungan pada tabel 2 antara kelompok eksperimen melalui penerapan pembelajaran TGT berbantuan media kartu soal antara kelompok kontrol dengan penerapan pembelajaran TGT tanpa media kartu soal memiliki nilai Sig.(2-tailed) $(0,028)<0,05$, maka ada perbedaan hasil belajar sehingga dapat disimpulkan kelas eksperimen lebih efektif daripada kelas kontrol.

\section{B. Pembahasan}

Penelitian ini dilakukan untuk mengetahui Efektivitas Model Team Game Tournament Berbantuan Media Kartu Soal terhadap Hasil Belajar peserta didik pada Materi Struktur Atom. Efektivitas penggunaan media kartu soal dalam model TGT dapat dilihat saat dilakukan perlakuan lanjutan.Pada perlakuan lanjutan, diperoleh data berupa nilai rata-rata kedua kelompok yaitu 84,2 untuk kelompok kontrol dan 90,2 untuk kelompok eksperimen (tabel 1). Data nilai tersebut menunjukkan bahwa kelompok eksperimen mempunyai hasil belajar yang lebih tinggi dibandingkan dengan kelompok kontrol.

Berdasarkan nilai akhir, perolehannilai terendah dan tertinggi kelompok eksperimen, yaitu 75 dan 100, sedangkan nilai terendah dan tertinggi kelompok kontrol 65 dan 100.Perbedaan nilai-nilai tersebut tidak terlalu besar, tetapi pada kelompok kontrol masih terdapat nilai dibawah 70. Hal ini disebabkan karena penggunaan media kartu soal dalam model TGT dapat menumbuhkan keaktifan dan minat belajar mahapeserta didik.

Salah satu faktor yang dapat meningkatkan keaktifan peserta didik adalah metode pembelajaran. Tyasningsih, dkk. (2012: 2) menyatakan bahwa pembelajaran dengan menerapkan model TGT mampu mendorong peserta didik untuk terlibat aktif dalam proses 
pembelajaran. Faktor lain yaitu pembelajaran pada kelompok eksperimen yang menggunakan media kartu soal lebih menarik dan lebih menyenangkan dibandingkan dengan kelompok kontrol.

Mahapeserta didik dilatih menggunakan media kartu soal dengan mengerjakan latihan-latihan soal sambil berdiskusi dengan kelompoknya, hal ini dapat meningkatkan pemahaman dan keterampilan mahapeserta didik terhadap materi yang disajikan. Perolehan nilai terendah dikelompok kontrol dan eksperimen, dapat disebabkan karena mahapeserta didik kurang tertarik terhadap mata kuliah kimia dasar, dan beranggapan materi kimia itu sulit dipelajari, meskipun dengan pemberian media kartu soal dalam model TGT. Rendahnya nilai hasil belajar peserta didik dapat terjadi karena adanya faktor-faktor lain yang mempengaruhi prestasi belajar yaitu faktor internal dan faktor eksternal. Faktor internal adalah faktor yang timbul dari dalam diri peserta didik sendiri, seperti kecerdasan, kesehatan jasmani, minat, bakat, perhatian dan cara belajar. Faktor eksternal adalah faktor yang datang dari luar diri peserta didik, seperti lingkungan (keluarga, sekolah, dan masyarakat), maka faktor-faktor tersebut saling berhubungan antara satu dengan yang lainnya dalam mempengaruhi hasil belajar peserta didik (Ratumanan, 2004: 63).
Berdasarkan hasil analisis Independent-Samples T Test pada Tabel 2. dapat disimpulkan bahwa hasil belajar mahapeserta didik antara kelompok eksperimen dengan penerapan pembelajaran TGT berbantuan media kartu soal dan kelompok kontrol dengan penerapan pembelajaran TGT tanpa media kartu soal berbeda karena nilai Sig. $(0,028)$ $<0,05$. Marwah dkk (2014:262) data yang diperoleh dapat disimpulkan bahwa ada pengaruh yang signifikan dalam menggunakan media kartu struktur atom dan sistem periodik terhadap hasil belajar.

\section{SIMPULAN DAN SARAN SIMPULAN}

Pemberian media kartu soal dalam model TGT pada materi Struktur atom efektif terhadap hasil belajar Mahapeserta didik dengan nilai nilai Sig. $(0,028)<0,05$ , maka ada perbedaan hasil belajar sehingga dapat disimpulkan kelas eksperimen lebih efektif daripada kelas kontrol. Didukung dengan nilai terendah tertinggi kelompok eksperimen, yaitu 75 dan 100 dengan rata-rata 90,02, sedangkan kontrol 65 dan 100 dengan rata-rata 84,2.

\section{SARAN}

Tenaga pendidik sebaiknya selalu memberikan tes awal dan tes akhir dalam proses pembelajaran khususnya materi stuktur atom sehingga dapat terlihat 
peningkatan hasil belajar mahapeserta didik.

\section{UCAPAN TERIMA KASIH}

Dekan FKIP yang telah mefasilitasi penelitan ini hingga dapat dilaksana dengan baik.

\section{DAFTAR PUSTAKA}

Kadir, 2016, Statistik Terapan: Konsep Contoh dan Analisis Data dengan Program SPSS/Lisrel dalam Penelitian, Depok; Rajawali;

Marwah, Sri M.S., \& I Made T. (2014). Pengaruh Penggunaan Media Kartu Stuktur Atom dan Sistem Periodik Terhadap Hasil Belajar Peserta didik Kelas XI SMA Negeri 6 Palu. Jurnal Akademi Kimia, 3(1), 36-41;

Ratumanan, Tanwey Gerson. 2004. Belajar dan Pembelajaran: Unesa University;

Rahmawati, A., \& Yonata, B. (2012). Keterampilan Social Pada Materi Reaksi Reduksi Oksidasi Melalui Penerapan Model Pembelajaran Kooperatif Tipe Numbered Head Together (NHT) SMA Negeri 9 Surabaya. Unesa Journal of Chemical Education, 1(1), 47-55;
Tyasningsih, Diah Megasari. Haryono. Nurhayati, Nanik Dwi. 2012. Penerapan Model Pembelajaran TGT (Teams Games Tournament) dilengkapi LKS untuk Meningkatkan Aktivitas dan Hasil Belajar Materi Minyak Bumi pada Peserta didik Kelas X-4 SMA Batik 1 Surakarta Tahun Pelajaran 2011/2012. Jurnal Pendidikan Kimia, Program Studi Pendidikan Kimia. Universitas Sebelas Maret;

Wijayati, N., Susilaningsih, E., \& Sari, Y. A. (2009). Peningkatan Life Skillpeserta didik Dalam Pembelajaran Kimia Dengan Menggunakan Pendekatan Game Simulation. Jurnal Inovasi Pendidikan Kimia, 3(1), 354-359.

Sugiyono. 2017. Statistika untuk Penelitian. Bandung: Alfabeta; 